Document downloaded from:

http://hdl.handle.net/10251/176386

This paper must be cited as:

Rendon-Patiño, A.; Santiago-Portillo, A.; Vallés-García, C.; Palomino Roca, M.; Navalón Oltra, S.; Franconetti, A.; Primo Arnau, AM.... (2020). Templateless Synthesis of UltraMicroporous 3D Graphitic Carbon from Cyclodextrins and Their Use as Selective Catalyst for Oxygen Activation. Small Methods. 4(3):1-9. https://doi.org/10.1002/smtd.201900721

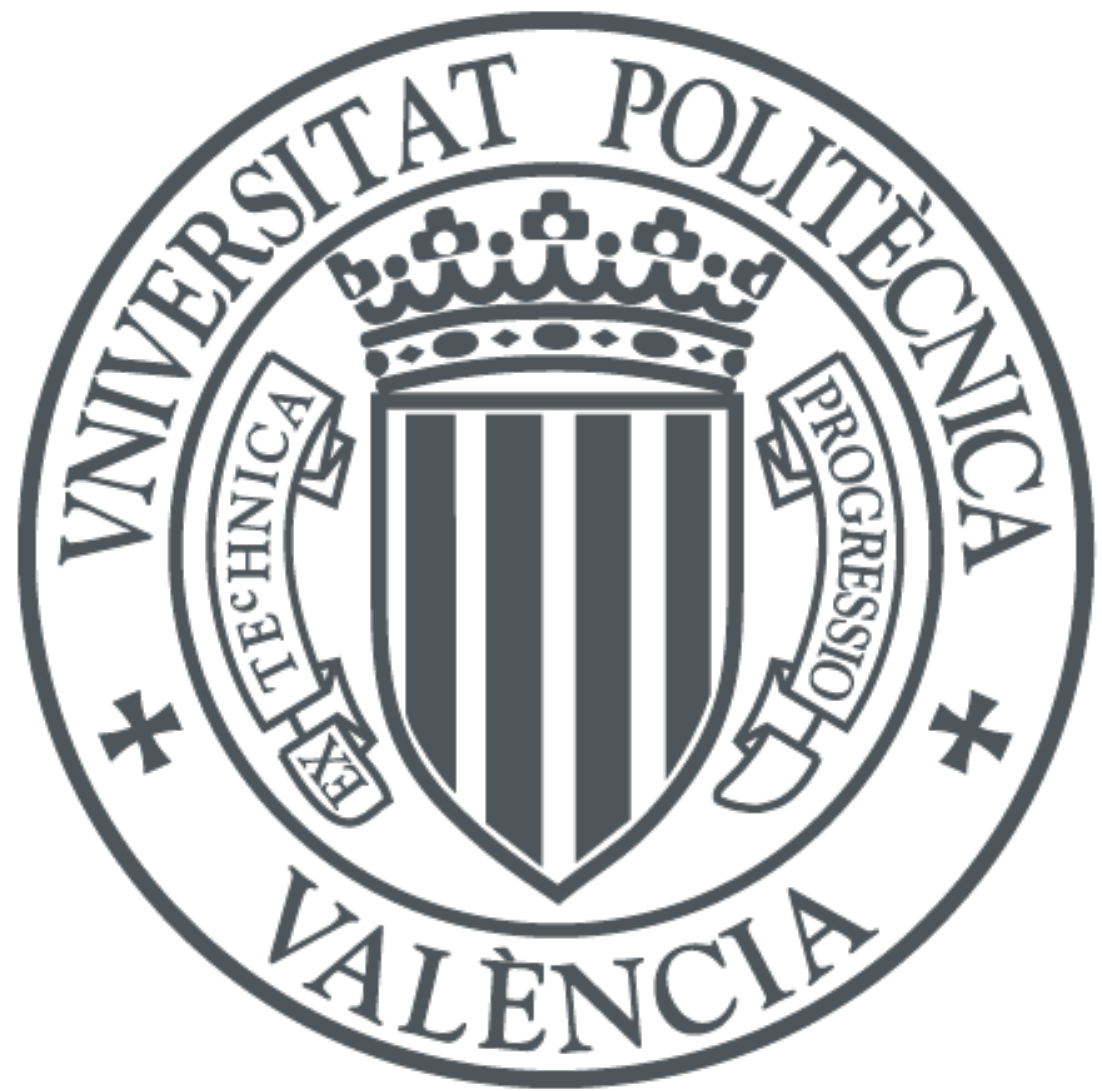

The final publication is available at

https://doi.org/10.1002/smtd.201900721

Copyright John Wiley \& Sons

Additional Information 


\section{Templateless Synthesis of Ultramicroporous 3D Graphitic Carbon from Cyclodextrins and their use as Selective Catalyst for Oxygen Activation}

Alejandra Rendón-Patiño, ${ }^{a}$ Andrea Santiago-Portillo, ${ }^{a}$ Cristina Vallés-Garcia, ${ }^{a}$ Miguel Palomino, ${ }^{a}$ Sergio Navalón, ${ }^{a}$ Antonio Franconetti, ${ }^{b}$ Ana Primo*a and Hermenegildo Garcia*a

PhD A. Rendón-Patiño, Dr. A. Santiago-Portillo, PhD C. Vallés-García, Dr. M. Palomino, Dr. S. Navalón, Dr. A. Franconetti, Dr. A. Primo, Prof. Hermenegildo García.

a Instituto de Tecnología Química (CSIC-UPV) and Department of Chemistry, Consejo Superior de Investigaciones Científicas-Universitat Politècnica de Valencia, Avenida de los Naranjos s/n, 46022 Valencia, Spain

b Departamento Química Orgánica, Facultad de Química, Universidad de Sevilla, Profesor García Gonzalez 1, 41012 Sevilla, Spain

Emaills: aprimoar@itq.upv.es; hgarcia@qim.upv.es

\section{Abstract.}

Pyrolysis of $\alpha-, \beta-$ and $\gamma$-cyclodextrins at $900{ }^{\circ} \mathrm{C}$ gives rise to the formation of crystalline graphitic porous nanoparticles $\left(\mathrm{G}_{\mathrm{CD}}\right)$, where the dimensions of the pores are uniform in the range from 0.63 to $0.97 \mathrm{~nm}$ from $\mathrm{G}_{\alpha-\mathrm{CD}}$ to $\gamma \mathrm{G}_{\gamma-\mathrm{CD}}$ as determined by transmission electron microscopy. It was found that, while for $\mathrm{G}_{\gamma-\mathrm{CD}}$ and $\mathrm{G}_{\gamma-\mathrm{CD}}$ the surface area measured by $\mathrm{N}_{2}$ adsorption was about 330 to $550 \mathrm{~m}^{2} \times \mathrm{g}^{-1}$, respectively, no area can be measured for $\mathrm{G}_{\alpha-C D}$ with $\mathrm{N}_{2}$ or Ar due to its small pore dimensions. However, $\mathrm{CO}_{2}$ adsorption reveals for $\mathrm{G}_{\alpha-\mathrm{CD}}$ the presence of ultramicroporosity and a surface area of $727 \mathrm{~m}^{2} \times \mathrm{g}^{-1} \cdot \mathrm{G}_{\mathrm{CD}}$ exhibit activity as metal-free catalysts for the aerobic oxidation of alcohols and the activity increases as the pore dimensions decreases. DFT calculations on models indicates that this 
high catalytic activity for $\mathrm{O}_{2}$ activation derives from confinement effects that favors charge transfer from the graphitic walls to $\mathrm{O}_{2}$. Studies on the formation mechanism shows that the key step leading to the formation of the channels is the melting of cyclodextrins precursors that makes possible the assembly of these capsules before their transformation into microporous graphitic particles.

\section{Introduction.}

Due to their large specific surface area in a small footprint, there is an increasing interest in structuring graphitic carbon as a tridimensional porous material with possible applications as electrocatalysts, supercapacitors and batteries. ${ }^{[1-3]}$ These $3 \mathrm{D}$ porous graphitic materials can be obtained by following two general methodologies, either the use of hard templates or hydrothermal treatment. ${ }^{[1-3]}$ In the majority of the cases, preformed graphene or graphene oxide were used as precursors in the formation of the 3D graphene, but chemical vapor deposition (CVD) synthesis using volatile precursors has also been reported. ${ }^{[1,4]}$ The target in this field is to obtain 3D graphitic powdered materials with large surface area approaching the theoretical value for a solid with walls constituted by single layer graphene, high mechanical stability and uniform pore size in the subnanometric range. ${ }^{[3]}$

Pyrolysis of sucrose, saccharides and polysaccharides may render graphitic carbon residues. ${ }^{[5,}$ ${ }^{6]}$ In a series of papers, it has been shown that powders of natural polysaccharides can form, after pyrolysis at temperatures above $800{ }^{\circ} \mathrm{C}$, graphitic particles that upon exfoliation render in a high yield defective graphenes. ${ }^{[7-9]}$ Defects in these graphenes consist in oxygenated functional groups, due to the residual $O$ content of the graphene. ${ }^{[7,10,11]}$ Other possible defects are carbon vacancies generated during the pyrolysis by evolution of $\mathrm{CO}_{2}, \mathrm{CO}$ and other gases. ${ }^{[7,10,11]}$ It has been typically found that the morphology of the precursor particles is maintained during the pyrolysis step, although particle dimensions shrink, even more than a half, due to the restructuring of the intermolecular distances and occurrence of $\pi-\pi$ stacking. ${ }^{[12]}$ Continuing with this line of research, it would be of interest to determine 
if other saccharides with peculiar morphology can also become transformed into some sort of graphitic carbon and which is the structure and properties of the resulting material.

In this context, cyclodextrins are cyclic oligomers of glucose with a number higher than five units, the most convenient ones being $\alpha, \beta$ and $\gamma$ cyclodextrin, with six, seven and eight glucose monomers, respectively. ${ }^{[13,14]}$ The difference in the number of glucose units determines the diameter of the organic capsule in the subnanometric scale. These organic molecules are soluble in water, but the less polar interior is appropriate to form in aqueous media supramolecular host (cyclodextrin)guest complexes with aromatic hydrocarbons and other types of molecules, provided that their size is smaller than the pore aperture ${ }^{[15,16]}$ Considering that cyclodextrins are widely available carbohydrates with a defined hollowed capsule morphology and that some acyclic carbohydrates can act as precursors of graphenes, ${ }^{[5,6]}$ it is of interest to submit cyclodextrins to pyrolysis to further advance in the knowledge of the structure and porosity of the resulting carbon residues and to determine their catalytic activity as a function of the precursor size. It was anticipated that, if formed, the pore dimensions of these materials would be correlated somehow with the dimensions of the $\alpha, \beta$ and $\gamma$ cyclodextrin used as precursor and this pore dimension can influence their catalytic activity. In one related precedent, formation of rod-like graphitic carbon nanostructures (microns length tubes, 10-40 $\mathrm{nm}$ diameter) evolving from structureless carbon was reported by pyrolysis of $\alpha$-cyclodextrin at temperatures higher than $1000{ }^{\circ} \mathrm{C} .{ }^{[17]}$ However, no attention was paid to the structure of the carbon nanorod precursor that appears at lower temperatures. In another study, $\alpha, \beta$ and $\gamma$ cyclodextrins and 6-deoxy $\beta$-cyclodextrin derivatives were submitted to pyrolysis as models of cellulose degradation, ${ }^{[18]}$ but the focus was on the analysis of the volatile products and not on the structure of the resulting carbons. ${ }^{[18]}$

Besides these two isolated precedents, the structure and catalytic activity of the carbon residues from cyclodextrins obtained at temperatures below $1000{ }^{\circ} \mathrm{C}$ remain undisclosed and their possible catalytic activity ignored. Particularly important is to determine the porosity and nature of the carbon material. As it would be shown later, TEM imaging and spectroscopic evidences, show that 
pyrolysis of $\alpha, \beta$ and $\gamma$ cyclodextrins at $900{ }^{\circ} \mathrm{C}$ renders microporous 3D graphitic materials whose porosity depends on the precursor dimensions. These 3D graphitic materials exhibit catalytic activity to promote aerobic oxidations with an activity that correlates with the size of the micropores. Theoretical calculations provide a rationalization of the influence of pore size on gas adsorption and the reasons why activation of molecular oxygen occur easier when the dimensions of the pores are commensurate with the size of molecular oxygen.

\section{Results and discussion.}

Pyrolysis of $\alpha, \beta$ and $\gamma$ cyclodextrins as powders was carried out in an electrical oven, heating at $5^{\circ} \mathrm{C} \cdot \mathrm{min}^{-1}$ up to $900^{\circ} \mathrm{C}$ with a holding time of $2 \mathrm{~h}$. In agreement with the thermogravimetric profiles (Figure 1a, inset), a weight loss about $80 \%$ was measured for the three cyclodextrins under study. This weight loss indicates that besides oxygen and hydrogen, about $50 \%$ of the carbon atoms are also removed in the pyrolysis, probably mostly as $\mathrm{CO}_{2}$, since otherwise the remaining mass of the carbon residue should have been $44 \%$. Similar thermogravimetric profiles as the one measured here have been previously determined. ${ }^{[17-19]}$

Combustion chemical analysis of the graphitic carbon residues $\left(\mathrm{G}_{\mathrm{CD}}\right)$ obtained by pyrolysis of $\alpha, \beta$ and $\gamma$ cyclodextrins indicates that they are constituted predominantly by carbon (see Table 1 ), but that there is still a significant percentage of residual oxygen, particularly for $\mathrm{G}_{\beta-C D}$ and $\mathrm{G}_{\gamma-\mathrm{CD}}$. In the case of $G_{\alpha-C D}$ the carbon content was the highest ever reported for graphitic carbons derived from pyrolysis of carbohydrates. ${ }^{[11]}$ Worth noting is the fact that the presence of small percentages of adventitious nitrogen was observed for the three samples. Since the molecular formula of cyclodextrins does not contain $\mathrm{N}$, the source of this minute $\mathrm{N}$ percentage detected for the three $\mathrm{G}_{\mathrm{CD}}$ by combustion analysis was intriguing. To determine the origin of $\mathrm{N}$, the commercial samples of the three cyclodextrins were also submitted to combustion analysis, observing the presence of a minute $\mathrm{N}$ percentage, of $0.01,0.01$ and $0.02 \%$ for $\alpha-, \beta$ - and $\gamma-C D$, respectively barely in the detection limit of 
the equipment. It is proposed that this minute $\mathrm{N}$ impurity is due to the imperfect purification of cyclodextrins after their enzymatic preparation, $\mathrm{N}$ becoming concentrated by a factor of 10 during the pyrolysis. Since $\mathrm{N}$ atoms on graphene are known to act as catalytic sites for certain reactions, ${ }^{[20]}$ their possible role in promoting the aerobic oxidation should be considered. It should be noted, however, that the $\mathrm{N}$ content of the three samples is very similar within $0.07 \%$ difference.

Raman spectra of the three $G_{C D}$ samples were similar, exhibiting three peaks appearing at 2800 (broad), 1590 and $1350 \mathrm{~cm}^{-1}$ corresponding to the expected 2D, G and D peaks, respectively, characteristic of defective graphenes. ${ }^{[21,22]}$ Figure $X X$ in the supporting information presents the Raman spectra for the three $G_{C D}$ under study. The relative intensity of the $G$ vs the $D$ band $\left(I_{G} / I_{D}\right)$ in the three $G_{C D}$ ranges from 1.15 to 1 that is in accordance with the $I_{G} / I_{D}$ ratios reported for other defective graphenes obtained by pyrolisis of carbohydrates. ${ }^{[7,8,10,23]}$ As an example, Figure S1 shows an illustrative Raman spectra for $\mathrm{G}_{\alpha-\mathrm{CD}}$.

Surface area and porosity measurements were carried out initially by isothermal $\mathrm{N}_{2}$ absorption at $77 \mathrm{~K}$. The results are also given in Table 1. As it can be seen there, specific surface area values of 331 and $454 \mathrm{~m}^{2} \cdot \mathrm{g}^{-1}$ were measured for $\mathrm{G}_{\beta-C D}$ and $\mathrm{G}_{\gamma-\mathrm{CD}}$, with a pore size about $2.3 \mathrm{~nm}$. Figure $\mathrm{S} 2$ shows a representative $\mathrm{N}_{2}$ absorption plot and the corresponding pore size distribution determined from the desorption branch. Importantly, similar type of measurements for $\mathrm{G}_{\alpha-C D}$ did not give any area value. We speculated that this could be due to the small pore size of $G_{\alpha-C D}$ that would be impossible to be determined by $\mathrm{N}_{2}$ absorption. To provide evidence in support of this claim, porosity of $\mathrm{G}_{\alpha-C D}$ was also measured using Ar at $77 \mathrm{~K}$ and also a specific surface area value of $0 \mathrm{~m}^{2} \cdot \mathrm{g}^{-1}$ was obtained. On the contrary, the surface area of $\mathrm{G}_{\alpha-\mathrm{CD}}$ was measured by $\mathrm{CO}_{2}$ absorption and a value of $727 \mathrm{~m}^{2} \cdot \mathrm{g}^{-1}$ and narrow pore distribution of $7.5 \AA$ is obtained (See Figure S3 in supporting information). Analogous measurements were also carried out for $\mathrm{G}_{\beta-\mathrm{CD}}$ and $\mathrm{G}_{\gamma-\mathrm{CD}}$. The corresponding values are also included in Table 1. As it can be seen there, for the three $G_{C D}$ samples under study, the specific surface area determined by $\mathrm{CO}_{2}$ adsorption at $273 \mathrm{~K}$ was higher than that estimated by $\mathrm{N}_{2}$ adsorption at $77 \mathrm{~K}$. The 
most remarkable case was, however, that of $\mathrm{G}_{\alpha-\mathrm{CD}}$. There are precedents in the literature showing differences in specific surface area values depending on the use of $\mathrm{N}_{2}$, $\operatorname{Ar}$ or $\mathrm{CO}_{2}$ that are attributed to the different kinetic diameter of $\mathrm{CO}_{2}(0.300 \mathrm{~nm}), \operatorname{Ar}(0.340 \mathrm{~nm})$ and $\mathrm{N}_{2}(0.364 \mathrm{~nm})$ and the different adsorption temperatures, ${ }^{[24,25]}$ the first being able to measure ultramicroporosity, ${ }^{[25]}$ i.e., pores below $0.5 \mathrm{~nm}$ diameter. It is proposed that the same is happening in the present case, the discrepancy between the absence of porosity in the $\mathrm{N}_{2}$ and $\mathrm{Ar}$ measurement with the $\mathrm{CO}_{2}$ adsorption being due to the exquisite discrimination of the pores of $G_{\alpha-C D}$ between both gases. In this way, the difference between the specific surface area values measured by $\mathrm{CO}_{2}$ and $\mathrm{N}_{2}$ is attributed to the surface area corresponding to ultramicropores. ${ }^{[26,27]}$ We will come back later to this issue when describing the theoretical models for $G_{C D}$ and the reasons for their higher activity of $G_{\alpha-C D}$ to promote catalytic $\mathrm{O}_{2}$ oxidations in comparison to the other congeners.

Table 1. Analytical and textural data of graphitic carbon residues obtained by pyrolysis of $\alpha, \beta$ and $\gamma$ cyclodextrins

\begin{tabular}{|c|c|c|c|c|}
\hline Sample & $\% \mathrm{Ca}^{a}$ & $\% \mathrm{Na}^{a}$ & $\begin{array}{l}\text { Surface area } \\
\qquad\left(\mathrm{m}^{2} / \mathrm{g}\right)^{\mathrm{b}}\end{array}$ & $\begin{array}{l}\text { Pore volume } \\
\qquad\left(\mathrm{cm}^{3} / \mathrm{g}\right)^{\mathrm{b}}\end{array}$ \\
\hline $\mathrm{G}_{\alpha-C D}$ & 95.44 & 0.20 & $0(727.54)$ & 0 \\
\hline $\mathrm{G}_{\beta-\mathrm{CD}}$ & 88.06 & 0.13 & 331.01 (596.76) & 0.163 \\
\hline $\mathrm{G}_{\gamma-\mathrm{CD}}$ & 87.41 & 0.14 & 453.65 (632.05) & 0.223 \\
\hline
\end{tabular}

$\mathrm{XRD}$ of the resulting carbon material after the pyrolysis indicates that it corresponds to a poorly crystalized graphitic carbon, observing broad peaks at $2 \Theta 25$ and $42^{\circ}$. Even more importantly, a sharp -6 - 
peaks at $11.92^{\circ}$ for $G_{\alpha-C D}$, at $4.45^{\circ}$ for $G_{\beta-C D}$ and $4.25^{\circ}$ for $G_{\gamma-C D}$ were recorded (Figure 1, b, $c$ and d). Figure $X X$ in the supporting information provides an expansion of the short angle region for the diffraction patterns of $G_{\beta-C D}$ and $G_{\beta-C D}$, where the minor shift in the position of the peaks can be seen. It is proposed that these peaks correspond to the assembly of the cyclodextrin units generating a regular channel structure. The diameter of the channel can be determined applying the Bragg equation to this peak corresponding to a pore diameter of 0.74 for $G_{\alpha-C D}$, while they increase in dimension for $G_{\beta-C D}$ and $\mathrm{G}_{\gamma-\mathrm{CD}}$ Observations of this low-angle diffraction peak is unique and it has not been previously observed for any of the graphitic carbon residues derived from polysaccharides. ${ }^{[17]}$ Another notable difference between $G_{C D}$ and the graphitic carbon residues derived from pyrolysis of polysaccharides was that in the case of natural polysaccharides constituted by polymeric fibrils, the graphitic residue can be efficiently exfoliated upon sonication, forming suspensions of defective graphenes in quite high yield. ${ }^{[7]}$ However, in the present case, sonication of the carbon residues from cyclodextrins $\left(G_{C D}\right)$ does not result in exfoliation and it was not possible to obtain significant yields of persistent single or few layers graphene suspensions upon prolonged high-power ultrasound treatment of $\mathrm{G}_{\mathrm{CD}}$. This point will be commented later when discussing the structure of $\mathrm{G}_{\mathrm{CD}}$ determined by electron microscopy images. 

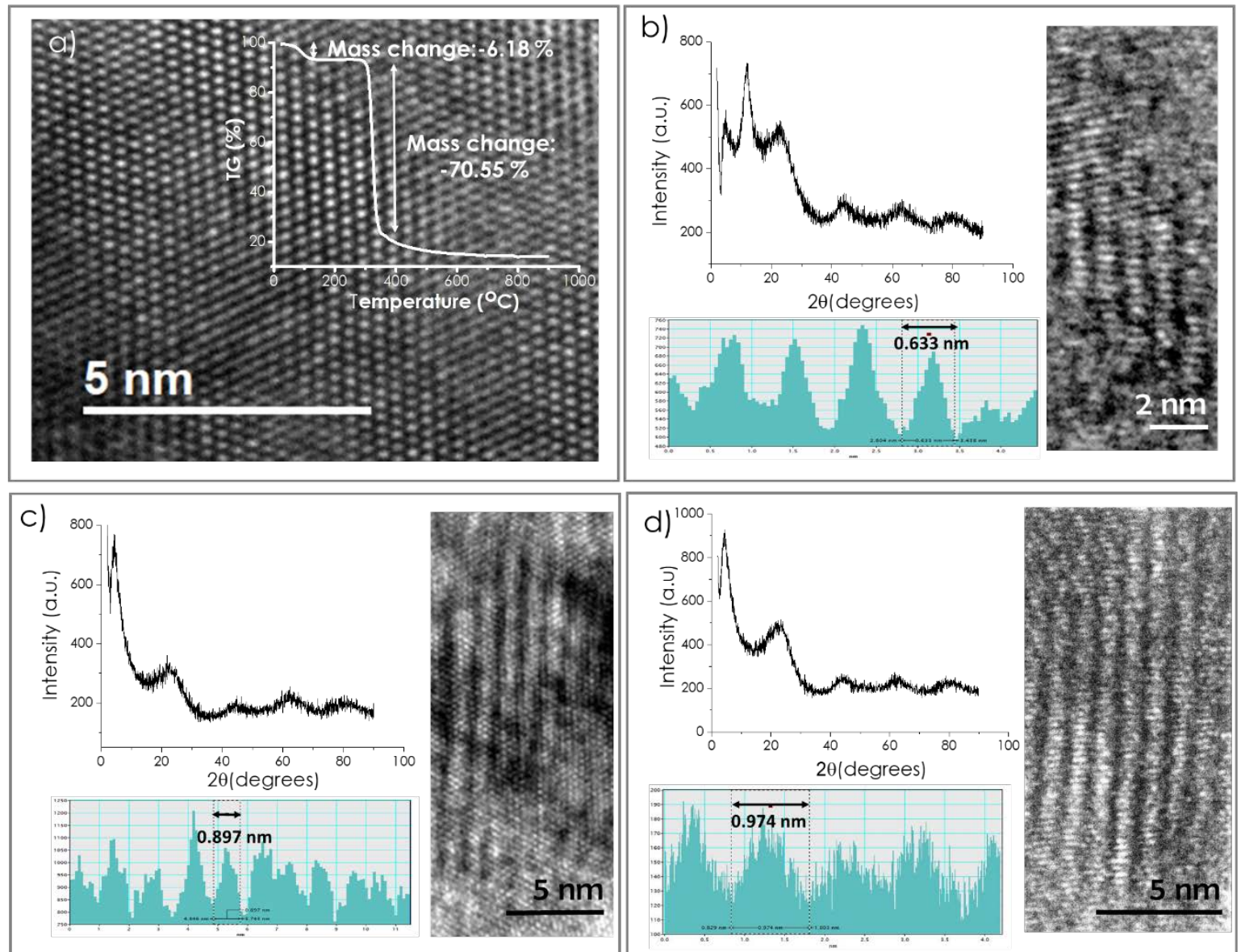

Figure 1. a) High resolution TEM image showing the high crystallinity of $G_{\alpha-C D}$. Inset: Thermogravimetric profile under $\mathrm{N}_{2}$ of $\mathrm{G}_{\alpha-\mathrm{CD}}$. $\mathrm{XRD}$, TEM images showing the channel structure and the dimensions of the corresponding channels of b) $G_{\alpha-C D}$ C) $G_{\beta-C D}$ and d) $G_{\gamma-C D}$.

The structure of $G_{C D}$ and the differences among them as a function of the cyclodextrin precursor are clearly revealed by transmission electron microscopy (TEM). Figure 1 shows selected images to illustrate the high crystallinity of the material, indicating that they correspond to graphitic carbons. Importantly, the presence of channels was clearly observed in the three samples. By measuring the periodic contrast fluctuation in the image between wall and pore, the dimensions of these channels were estimated as $0.633,0.807$ and $0.974 \mathrm{~nm}$ for $G_{\alpha-C D}, G_{\beta-C D}$ and $G_{\gamma-C D}$, respectively (see Figure 1). Based on these TEM measurements, a constant increment of about $0.17 \mathrm{~nm}$ was 
calculated for each additional glucose unit in the cyclodextrin precursor from $\alpha$ to $\gamma$. According to these TEM images and the microporosity observed in gas adsorption, it is proposed that these channels are derived from the assembly of conical cyclodextrin capsules as tubes during the pyrolysis process as depicted in Scheme 1. It has been previously observed that the conical shape of cyclodextrins favors their assembly as tubes under certain conditions in solution ${ }^{[17]}$ and it could be that the same type of arrangement occurs in the cyclodextrin crystals that should melt during the process for a certain period (estimated melting point of cyclodextrins between 260 and $\left.300{ }^{\circ} \mathrm{C}\right)^{[18]}$ before occurrence of the profound chemical transformation leading to $G_{C D}$. According to Scheme 1, the cyclodextrin melt and the high temperatures should allow molecular arrangement as microtubules that undergo fusion into channels in subsequent steps.

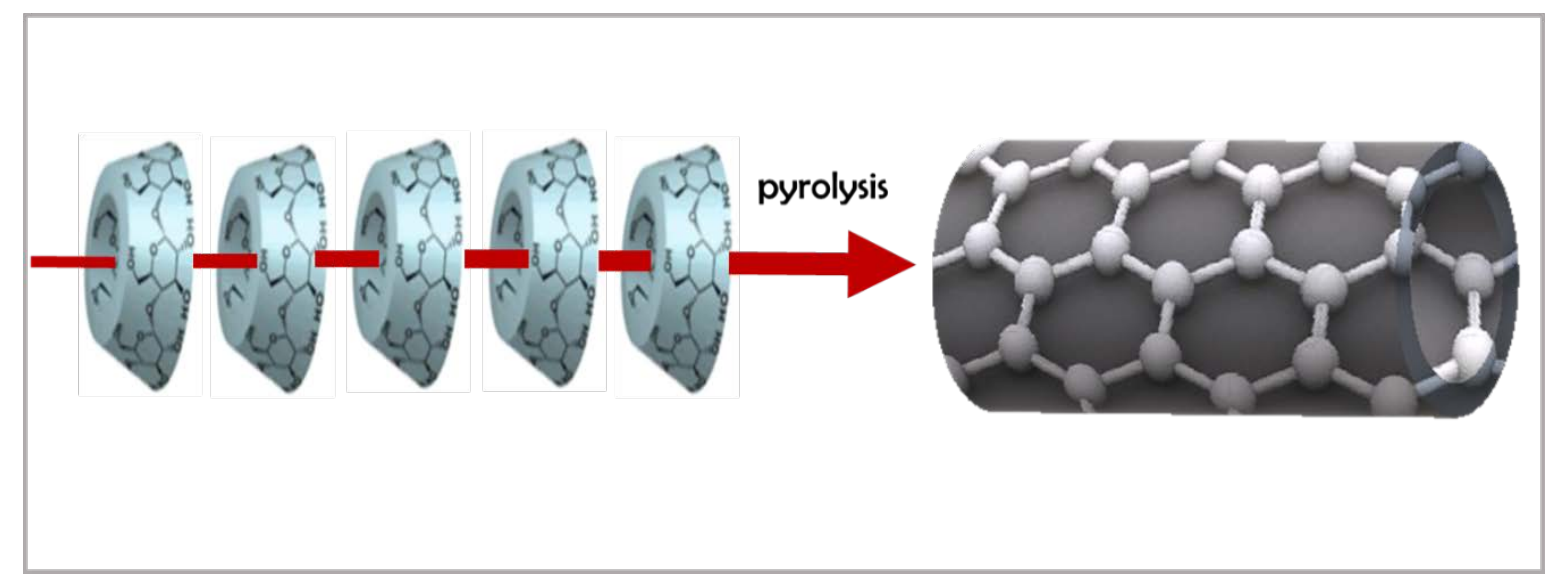

Scheme 1. Pictorial illustration of the assembly of conical cyclodextrin capsules as graphitic tubes during the pyrolysis process.

To provide some support to this hypothesis, $\alpha, \beta$ and $\gamma$ cyclodextrins were melt at $300{ }^{\circ} \mathrm{C}$ and this temperature held during $2 \mathrm{~h}$. After this time, the samples were cooled down at ambient temperature and the resulting annealed solids were analyzed by XRD and TEM. Figure S4 in the supporting information provides the XRD patterns of commercial cyclodextrins and those recorded after melting and $2 \mathrm{~h}$ annealing compared to those of $\mathrm{G}_{\mathrm{CD}}$. As it can be seen in Figure S4, the XRD 
patterns of the cyclodextrins after melting are similar to those of the graphitic carbon residues $\mathrm{G}_{\mathrm{CD}}$ and totally different from those of the commercial powders. This similarity after the melt and those of $\mathrm{G}_{\mathrm{CD}}$ indicates that structuration into channels can occur in the melt. This proposal was further confirmed by TEM images of the cyclodextrins that were melt at $300{ }^{\circ} \mathrm{C}$ and, then, cooled down at room temperature. Figure $X X$ in the supporting information shows a representative set of these images, where the presence of the channels due to assembly of the cyclodextrins in the liquid phase can be clearly seen.

\section{Catalytic activity}

One of the main applications of defective graphene and related graphitic carbons is as metalfree catalyst. ${ }^{[28,29]}$ Among the different types of reactions that can be promoted by defective graphenes, aerobic oxidation of hydrocarbons and alcohols is among of the most general ones. ${ }^{[29]}$ Therefore, it was of interest to determine the catalytic activity of $G_{C D}$ for this type of reaction and particularly if there is an influence of the pore size in the critical range distinguishing gas molecules on the catalytic activity. In the most general reaction mechanism, molecular oxygen is activated by the catalyst forming superoxide or other reactive oxygen species that are able to trigger a reaction chain mechanism.

Aimed at determining the catalytic activity of $G_{C D}$ for aerobic oxidations, benzylic alcohol was selected as probe molecule. The reactions were carried out in toluene at $160{ }^{\circ} \mathrm{C}$ under 5 bar $\mathrm{O}_{2}$ pressure, in the absence of any base. Figure $2 \mathrm{a}$ shows the time-conversion plot for the aerobic oxidation of benzyl alcohol. Benzyl alcohol was converted into a mixture of benzaldehyde, benzoic acid and benzyl benzoate, with selectivity values depending on the conversion (see Figure S5 in supporting information). A clear relationship between the nature of the precursor and the catalytic activity of the resulting $G_{C D}$ was observed. Thus, the relative activity order was $G_{\alpha-C D}>G_{\beta-C D}>G_{\gamma-C D}$. $A$ 
comparison with the activity of commercial active carbon shows that any of the $\mathrm{G}_{\mathrm{CD}}$ is a more efficient catalyst than active carbon.
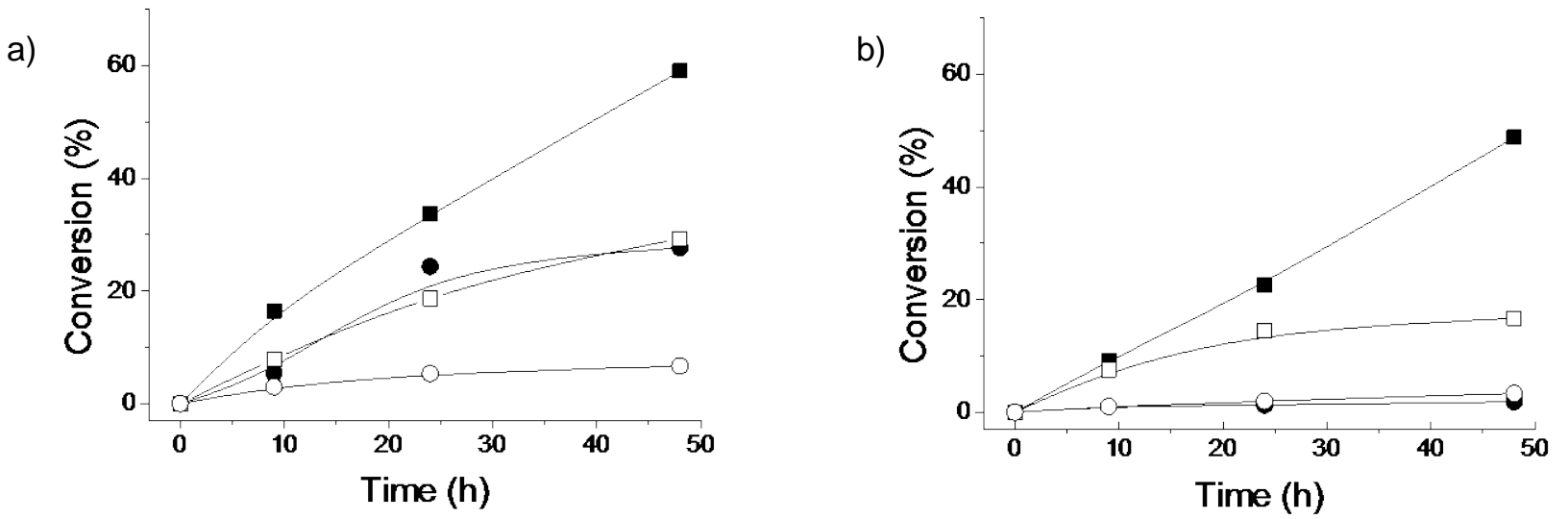

Figure 2. Time conversion plots for aerobic oxidation of a) benzyl alcohol and b) 1phenylethanol using the catalysts: $\backsim \mathrm{G}_{\alpha-C D}, \square \mathrm{G}_{\beta-C D}, \bullet \mathrm{G}_{\gamma-C D}$ or $\circ$ carbon activated. Reaction conditions: benzyl alcohol or 1-phenylethanol $1 \mathrm{mmol}$, toluene $2.5 \mathrm{~mL}$, catalyst $10 \mathrm{mg}, \mathrm{O}_{2}$ pressure 5 bars, temperature $160^{\circ} \mathrm{C}$.

Recyclability tests by using the same $\mathrm{G}_{\alpha-C D}$ sample in consecutive reactions indicate a gradual deactivation of the catalyst upon reuse (see Figure S6 in supporting information). Since reuse tests without toluene washings of the used $\mathrm{G}_{\alpha-\mathrm{CD}}$ catalyst results in a complete deactivation and the activity of the used $G_{\alpha-C D}$ catalyst depends largely on the washing process, it is proposed that the main deactivation pathway is clogging of the $G_{\alpha-C D}$ pores by substrate and products. Particularly carboxylic acids are well known poisons by strong interaction with the catalyst active sites.

Working under the same reaction conditions, the same activity order was measured for the aerobic oxidation of 1-phenylethanol that was selectively converting into acetophenone (Figure 2b). As in the case of benzyl alcohol, also for 1-phenylethanol, the commercial active carbon was notoriously inefficient to promote this aerobic oxidation. Although an almost complete conversion of 1phenylethanol to acetophenone was observed at long reaction times using $\mathrm{G}_{\alpha-\mathrm{CD}}$ as catalyst, the reaction was significantly slower as compared to benzyl alcohol oxidation (compare plots in Figure 2). 
This slower reactivity of 1-phenylethanol is proposed to be due to the steric encumbrance of secondary alcohols compared to primary alcohols. The aerobic oxidation of benzylic alcohol was also expanded to para substituted derivatives (Figure 3a). It was observed that 4-methoxybenzyl alcohol undergoes selective oxidation to the corresponding $p$-methoxybenzaldehyde somewhat faster than the parent benzyl alcohol, while 4-methylbenzyl alcohol undergoes oxidation significantly slower affording a mixture of 4-methylbenzaldehyde, 4-methylbenzoic acid and 4-methylbenzyl 4-methylbenzoate with selectivity values depending on the conversion (see Figure S5 in supporting information).

a)

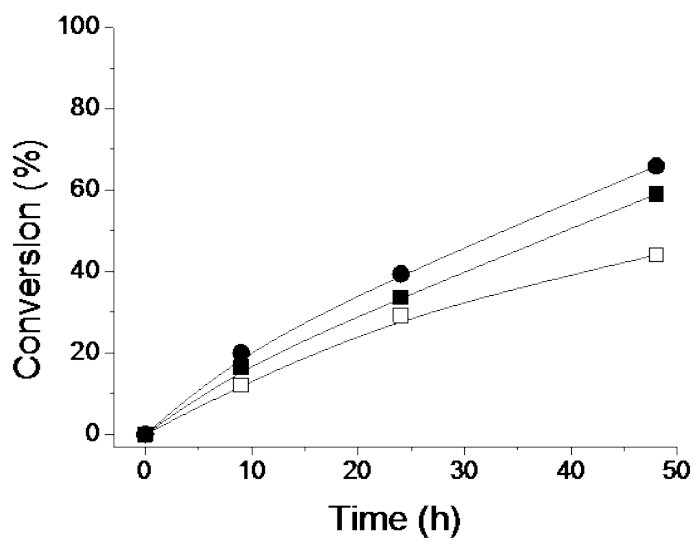

b)

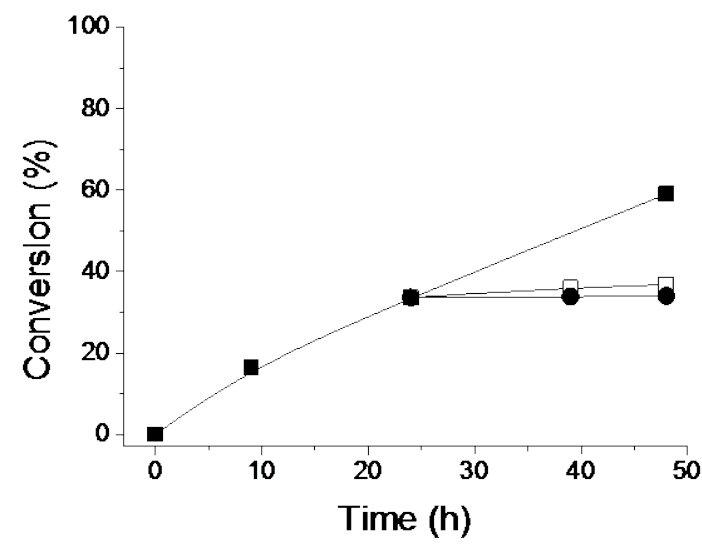

Figure 3. a) Time conversion plot for aerobic oxidation of different para substituted derivatives of benzyl alcohol a) $\mathrm{H} \square) \mathrm{CH}_{3} \bullet$ ) $\mathrm{CH}_{3} \mathrm{O}$ using $\mathrm{G}_{\alpha-\mathrm{CD}}$ as catalyst; b) Time conversion plot for aerobic oxidation of benzyl alcohol using $G_{\alpha-C D}$ as catalyst in the presence of different selective quenchers of reactive oxygen species •) without quencher; $\square) 20 \%$ DMSO; •) $20 \%$ p-benzoquinone.

The performance of $G_{\alpha-C D}$ as heterogeneous catalysts for aerobic oxidation of alcohols was also tested under the same conditions for aliphatic primary (1-octanol) and secondary (2-octanol) alcohol oxidation to the corresponding carbonylic compounds. In accordance with the expected relationship between the alcohol structure and reactivity, aliphatic alcohols undergo conversion to the corresponding carbonyl compounds at slower rate (see Figure S7 in supporting information), although a significant conversion was still achieved even for these aliphatic substrates at low reaction times. 
Regarding the reaction mechanism and particularly the nature of the reactive oxygen species involved on the aerobic alcohol oxidation, a series of benzyl alcohol oxidation reactions were carried out under the typical reaction conditions. In these reactions selective quenchers were added at $10 \mathrm{~h}$ reaction, when the conversion was about $40 \%$, to see their influence on the reaction evolution. The fact that the reaction was already initiated in the absence of quenchers ensures that all the possible oxygen reactive species involved have already been generated in the reaction mixture and have reached a steady-state concentration. The amount of quencher added to the reaction was 20 mol\% respect to the initial amount of benzyl alcohol. Since reactions involving reactive oxygen species are typically radical chain mechanisms, the presence of quencher in this proportion should be reflected in a significant change in the temporal conversion profile after its addition. As selective quenchers, $p$ benzoquinone to inhibit superoxide $\left(\mathrm{O}_{2}{ }^{-{ }^{-[30-33]}} \text { and dimethylsulfoxide (DMSO }\right)^{[34-36]}$ to intercept hydroxyl radicals $(\cdot \mathrm{OH})$ were used. The results are presented in Figure $3 \mathrm{~b}$. As it can be seen there, the reaction completely stops using $p$-benzoquinone as quencher indicating that $\mathrm{O}_{2}{ }^{--}$formed by single electron reduction of molecular dioxygen is the first species involved in the oxidation. More surprisingly is, however, the influence of DMSO that also inhibits in about $85 \%$ benzyl alcohol oxidation. This indicates that through a series of consecutive electron reduction-protonation, $\mathrm{O}_{2}{ }^{--}$most probably evolves to the formation of $\mathrm{H}_{2} \mathrm{O}_{2}$ that would generate $\cdot \mathrm{OH}$ radicals that would be responsible for most of the observed benzyl alcohol oxidation. Scheme 2 summarizes our proposal. 


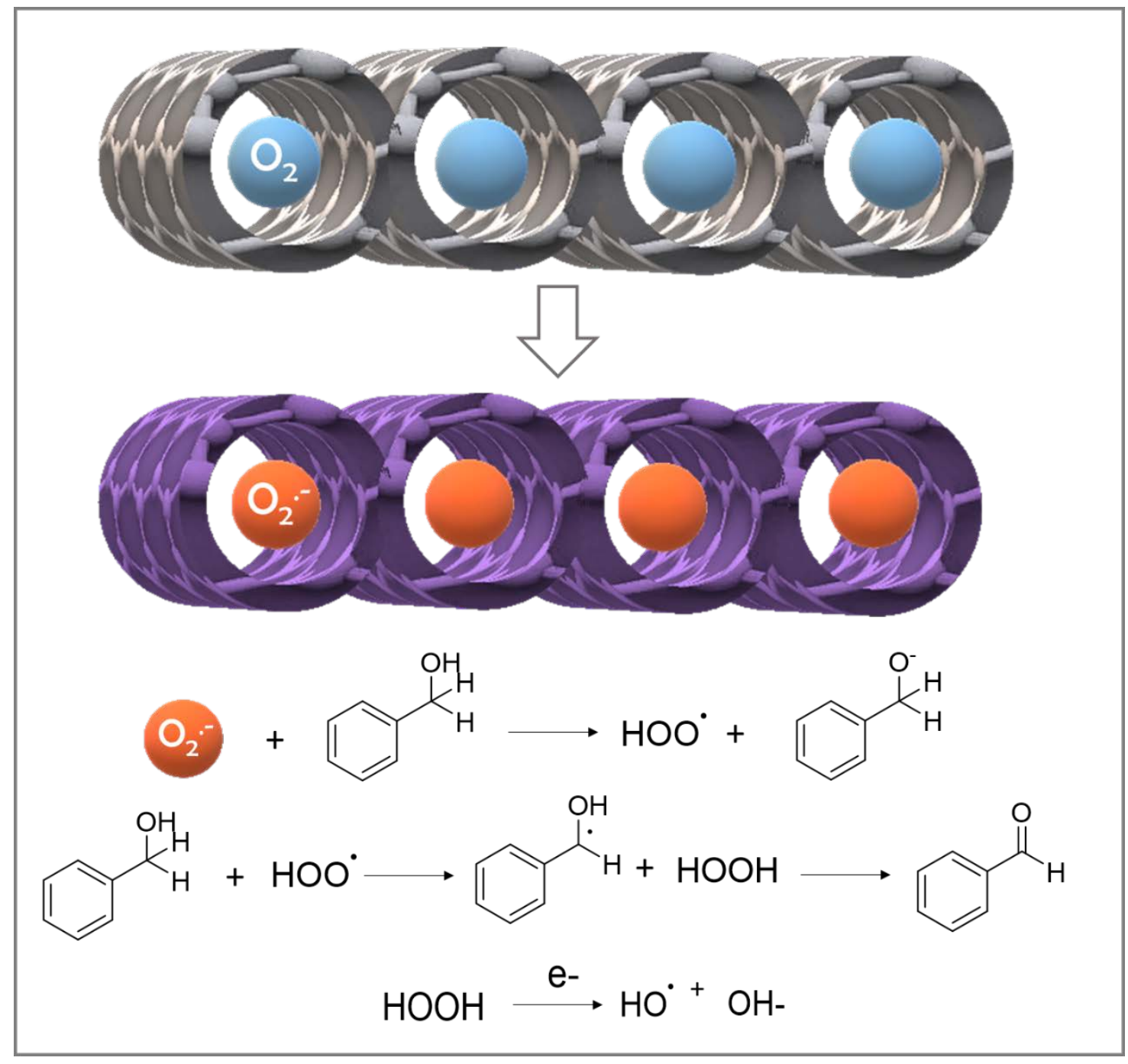

Scheme 2. Simplified reaction mechanism showing the initial generation of superoxide (in orange) within the channels from molecular $\mathrm{O}_{2}$ (in blue) and subsequent generation of hydroxyl radicals.

\section{Quantum Chemical Calculations}

In order to understand the reasons for the different gas adsorption on $G_{\alpha-C D}$ and its higher catalytic activity to promote aerobic alcohol oxidations compared to the other congeners, theoretical DFT calculations were carried out at PBE-D3/def2-SVP level. For this purpose, three kinds of defectfree $G_{C D}$ nanotubes $\left(G_{C D-1}\right.$ to $\left.G_{C D-3}\right)$ were firstly built to establish the possible influence of the pore size on the adsorption of $\mathrm{N}_{2}$ and Ar gases. Of note is that the pore dimensions and lengths of the models 
do not coincide with the experimental data. The models were built to provide insights into the trend in the influence of the pore dimension at a reasonable computational cost. The energy of these systems when $\mathrm{N}_{2}$ and Ar molecules pass through the $\mathrm{G}_{\mathrm{CD}}$ tube was determined (Figure 4).

In general, contacts between $\mathrm{N}_{2}$ or $\mathrm{Ar}$ and the edge of $\mathrm{G}_{\mathrm{CD}}$ tubes provided a local stabilization (up to $-0.2 \mathrm{eV}$ ) due to the interplay between these molecules and the hydrogen atoms of the surface periphery of the tubular models. Despite this fact, the results for $G_{C D-1}$ (Figure $4 A$ ), with the smallest pore size $(0.38 \mathrm{~nm})$, show that the interaction of $\mathrm{N}_{2}$ and $\operatorname{Ar}$ with the tubes are unfavorable. The estimated barriers for entering these gases inside the tube suggest that these energies cannot to be reached even at room temperature. Our second model $\mathrm{G}_{\mathrm{CD}-2}$ presents a higher pore size $(0.54 \mathrm{~nm})$ than $G_{C D-1}$. Based on the adsorption profile (Figure 4B) and the calculated energy barrier (up to 0.85 $\mathrm{eV}$ for $\mathrm{Ar}$ ), it could be possible that this pore size would allow both gases to enter inside the $\mathrm{G}_{\mathrm{CD}-2}$ model at room temperature. However, neither $\mathrm{N}_{2}$ nor Ar should not give any surface area value since isothermal adsorptions are carried out at $77 \mathrm{~K}$, and therefore, the energy barrier of $\mathrm{G}_{\mathrm{CD}-2}$ is too high to be reached under these conditions. 

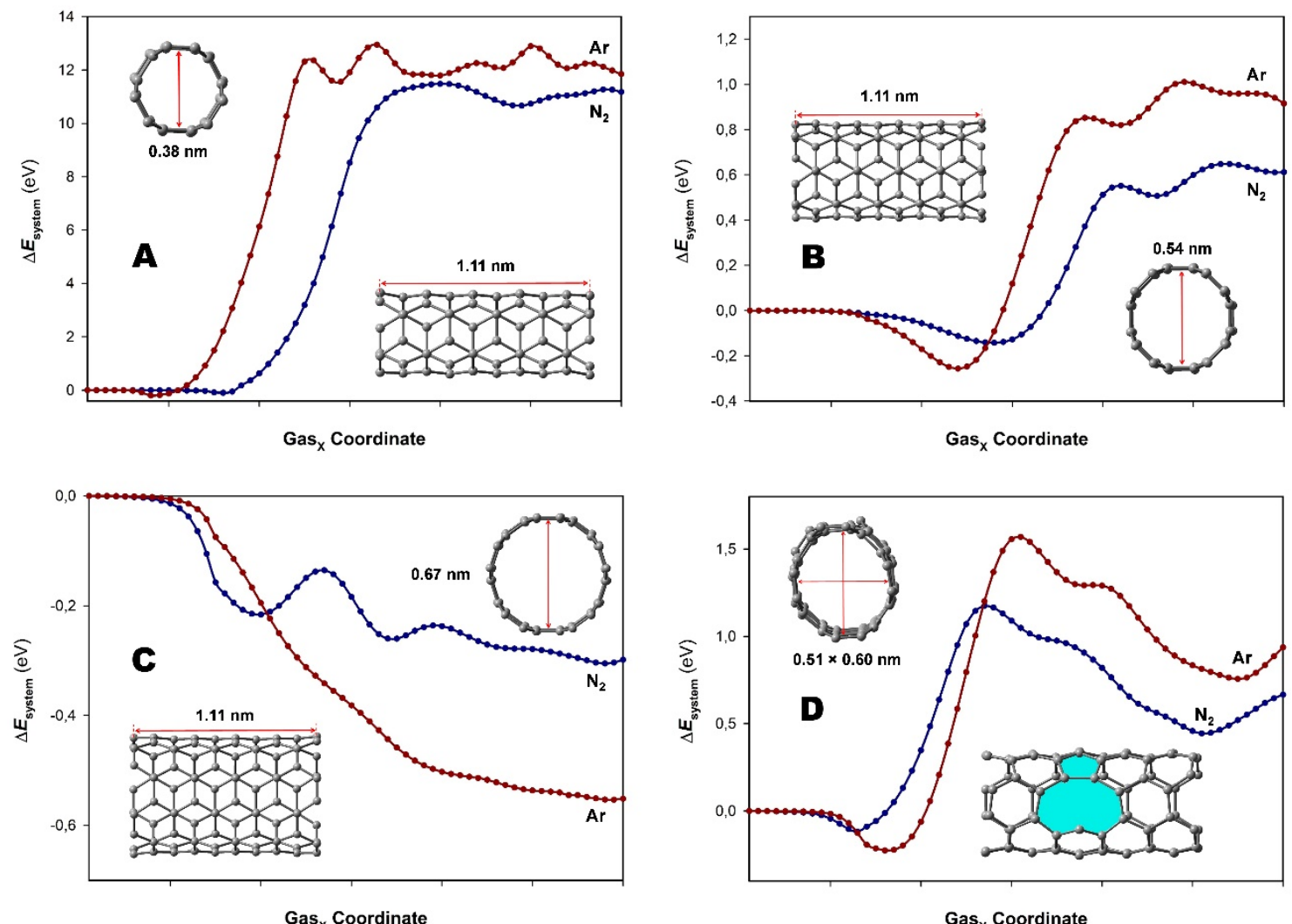

Gas $_{x}$ Coordinate

Figure 4. Theoretical adsorption profiles of $N_{2}$ and Ar gases for four different $G_{C D}$ models: $(A) G_{C D-1} ;(B)$

$\mathrm{G}_{\mathrm{CD}-2}$; (C) $\mathrm{G}_{\mathrm{CD}-3}$ and (D) defective $\mathrm{G}_{\mathrm{CD}-2}$ material. Hydrogen atoms at the opening of the tubes are omitted for clarity.

The last pore size studied $(0.67 \mathrm{~nm})$ corresponds to $\mathrm{G}_{\mathrm{CD}-3}$ model as shown in Figure $4 \mathrm{C}$. The calculated profile reveals that this material perfectly allows the adsorption of both gases even at temperatures below $298 \mathrm{~K}$. In addition, the interplay between $G_{C D-3}$ tube and $N_{2}(A r)$ follows the expected trend taking into account the kinetic diameter of these gases. Thus, the lower kinetic diameter of $\operatorname{Ar}(0.340 \mathrm{~nm})$ than $\mathrm{N}_{2}(0.364 \mathrm{~nm})$ induces that $A r$ fits better inside the tube being stabilized up to $-0.15 \mathrm{eV}$ regarding $\mathrm{N}_{2}$.

Using our experimental findings as jumping-off point, $\mathrm{G}_{\mathrm{CD}-2}$ was selected (pore size of $0.54 \mathrm{~nm}$ ) to further understand the activation of $\mathrm{O}_{2}$ molecule. It is known that the activation of different molecules such as $\mathrm{H}_{2}$ or $\mathrm{O}_{2}$ by graphene can take place at carbon atom vacancies $\left(\mathrm{V}_{\mathrm{c}}\right)^{[37]}$ that is a probable defect of $G_{\alpha-C D}$. As commented, Raman spectra of $G_{C D}$ materials shows the expected peaks 
corresponding to defective graphenes and the high $C$ content of $G_{\alpha-C D}$ makes oxygenated functional groups as less probable. For that reason, a monovacancy was optimized on $\mathrm{G}_{\mathrm{CD}-2}$ model resulting on the appearance of a 5- and another 9-membered ring, that means, a 5/9 vacancy (Figure 4D).

As commented above, the surface area of $\mathrm{G}_{\mathrm{a}-\mathrm{CD}}$ could be determined using $\mathrm{CO}_{2}$. Therefore, besides $\mathrm{N}_{2}$ and $\mathrm{Ar}$, it was of interest to compute the adsorption profiles of $\mathrm{CO}_{2}$ gas for both defect-free and defective materials. The results obtained indicate that $\mathrm{CO}_{2}$ can diffuse at room temperature in both defect-free and defective $\mathrm{G}_{\mathrm{CD}-2}$ models (Figure $5 \mathrm{~A}$ ) in agreement with experimental findings.

The introduction of one vacancy on the surface provokes different features. Firstly, a distortion of $\mathrm{G}_{\mathrm{CD}-2}$ tube that slightly changes the pore size $(0.51 \times 0.60 \mathrm{~nm})$ modifying the adsorption profile and the energy barrier for entering inside the tube (Figure 4D and 5A). Secondly, MEP surfaces show a local negative region $(-1.6 \mathrm{eV})$ around the vacancy hole in comparison to defect-free model (Figure 5B). The carbon vacancy defect and its surroundings have a direct influence on adsorptions of $\mathrm{N}_{2}, \mathrm{Ar}$ and $\mathrm{CO}_{2}$ gases stabilizing them at this position. Therefore, the presence of defects is envisioned optimal for activation of $\mathrm{O}_{2}$ molecules inside the carbon tube. In this context, a $\Delta E_{\text {ads }}$ value of -9.6 $\mathrm{kcal} / \mathrm{mol}$ points toward a favorable stabilization of $\mathrm{O}_{2}$ on the vacancy hole (Figure $5 \mathrm{C}$ ). In addition, other parameters also lead to an effective activation of $\mathrm{O}_{2}$ molecule since a slight lengthening of $\mathrm{O}=\mathrm{O}$ bond $(\Delta R=0.02 \AA)$ was calculated as well as a difference of density charge between oxygen atoms (Mulliken charge difference $=0.04$ a.u.). 

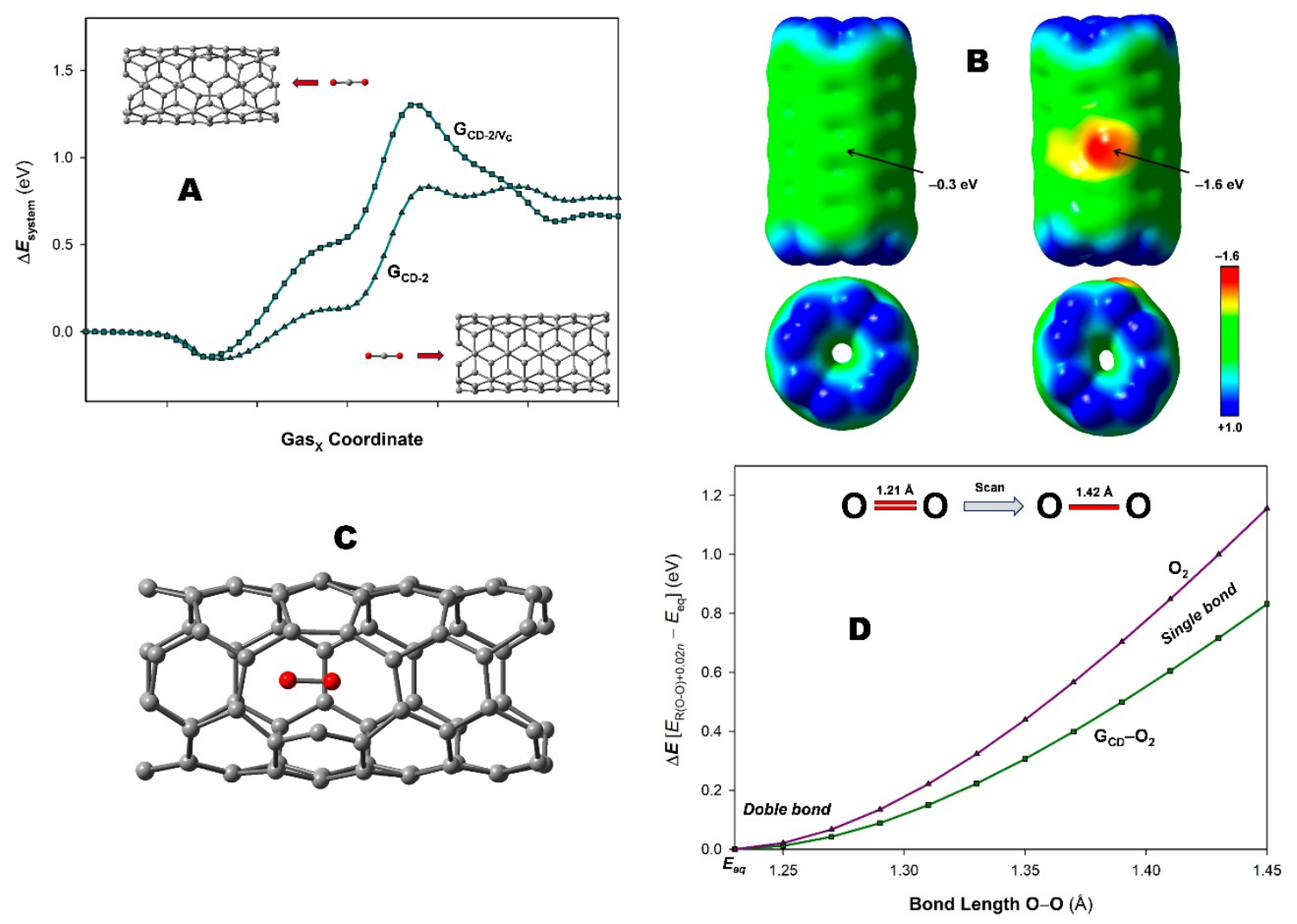

Figure 5. Theoretical outcomes at PBE-D3/def2-SVP level for: (A) adsorption profiles of $\mathrm{CO}_{2}$ gases for $\mathrm{G}_{\mathrm{CD}-2}$ and $\mathrm{G}_{\mathrm{CD}-2 / N c}$ materials; (B) MEP surfaces (0.001 a.u.) of $\mathrm{G}_{\mathrm{CD}-2}$ (left) and $\mathrm{G}_{\mathrm{CD}-2 / \mathrm{Nc}}$ material (right); (C) Adsorption of a ground state $\mathrm{O}_{2}$ molecule on a carbon monovacancy; and (D) plot of bond energy increment respect to the $\mathrm{O}=\mathrm{O}$ value as a function of the $\mathrm{O}-\mathrm{O}$ bond length either in vacuum and in the interior of $G_{C D}$ tube.

The activation of a ground state $\mathrm{O}_{2}$ molecule should proceed through a remarkable lengthening of $\mathrm{O}-\mathrm{O}$ bond length from a double $\mathrm{O}=\mathrm{O}$ bond to single $\mathrm{O}-\mathrm{O}$ bond. The main feature of $\mathrm{G}_{\mathrm{CD}}$ material arise from the capability to stabilize $\mathrm{O}_{2}$ molecules, while lengthening of $\mathrm{O}-\mathrm{O}$ is taking place (Figure $5 \mathrm{D})$. In fact, the penalty caused by the lengthening of O-O bond inside the tube is only 0.5 eV (11.5 $\mathrm{kcal} / \mathrm{mol})$ at bond lengths around $1.40 \AA$ whereas a penalty of $0.7 \mathrm{eV}(16.2 \mathrm{kcal} / \mathrm{mol})$ was found for single $\mathrm{O}_{2}$ molecule in vacuum. Thus, $\mathrm{O}_{2}$ activation is easier inside the $\mathrm{G}_{\mathrm{CD}}$ tube. 


\section{Conclusions}

It has been shown that pyrolysis of $\alpha, \beta$ and $\gamma$ cyclodextrins forms microporous graphitic particles with regular channel dimensions that are correlated with the diameter of the cyclodextrin precursor. Particularly, in the case of $\mathrm{G}_{\alpha-\mathrm{CD}}$ the discrepancy between isothermal $\mathrm{N}_{2}$ and $\mathrm{Ar}$ adsorption with that of $\mathrm{CO}_{2}$ at the same temperature indicates that this material is the one in the series exhibiting ultramicroporosity able to discriminate between the kinetic dimensions of these gases. Molecular modeling shows the adsorption energy of $\mathrm{N}_{2}$ molecules inside a cylindric tube of hexagonal $\mathrm{sp}^{2}$ carbon atoms depends on the diameter of the tube in the range from 0.38 to $0.67 \mathrm{~nm}$, there being a threshold that makes possible the entrance of $\mathrm{N}_{2}$ inside the tube. Interaction with $\mathrm{O}_{2}$ indicates that bond elongation resulting in the formation of superoxide is less uphill when there is a tight fit of $\mathrm{O}_{2}$ inside the graphene channels.

In accordance with the general activity of carbonaceous materials as oxidation catalysts, all the three $G_{C D}$ promote the aerobic oxidation of benzyl alcohol in the presence of base. However, it was observed that the initial reaction rate correlates with the pore diameter. $G_{\alpha-C D}$ is the most effective of the series and is able to promote the aerobic oxidation of benzylic primary and secondary as well as aliphatic alcohols, through a mechanism that involves the initial formation of superoxide and where . $\mathrm{OH}$ radicals contribute about $85 \%$.

The present results illustrate the possibility to form structured graphitic carbons with regular microporosity in the subnanometric range starting from cyclodextrins. It can be predicted that the same methodology can be applied for other hollow organic capsules and their derivatives. 


\section{Experimental Section}

\section{Methods}

\section{$\mathbf{G}_{\mathrm{CD}}$ Preparation}

Pyrolysis of commercial cyclodextrins (Aldrich) was carried out using an electric horizontal oven under $\mathrm{N}_{2}$ flow (200 ml $\times \mathrm{min}^{-1}$ ) and using the following heating program: annealing at $300^{\circ} \mathrm{C}$ for $2 \mathrm{~h}$ by increasing the temperature from room temperature at a rate of $5^{\circ} \mathrm{C} \times \mathrm{min}^{-1}$, then heating at $1^{\circ} \mathrm{C} \times \mathrm{min}^{-}$

${ }^{1}$ up to $900^{\circ} \mathrm{C}$ and a holding time of $2 \mathrm{~h}$. Then, the sample was cooled down at room temperature maintaining the $\mathrm{N}_{2}$ flow.

\section{Catalytic measurements}

$10 \mathrm{mg}$ of the corresponding catalyst $\left(\mathrm{G}_{\alpha-\mathrm{CD}}, \mathrm{G}_{\beta-\mathrm{CD}}, \mathrm{G}_{\gamma-\mathrm{CD}}\right)$ dispersed in $2,5 \mathrm{~mL}$ of toluene were introduced into a reactor vessel $(5 \mathrm{~mL})$. Subsequently, the alcohol reagent $(1 \mathrm{mmol})$ was added to the reactor with 1 eq of $\mathrm{NaOH}$. The system was pressurized with $\mathrm{O}_{2}(5 \mathrm{~atm})$. In all cases, the reactions were carried out at $160{ }^{\circ} \mathrm{C}$ under magnetic stirring.

Selective radical quenching experiments were carried out following the general reaction procedure described, but with the addition of radical quenchers (20 mol \% with respect to the substrate). In this case, dimethylsulfoxide (DMSO) and p-benzoquinone were added as selective hydroxyl or superoxide/hydroperoxyl radical scavengers, respectively.

\section{Product analysis}

Previously filtered reaction aliquots were diluted in toluene containing a known amount of nitrobenzene as external standard. The aliquots were immediately analyzed by gas chromatography using a flame ionization detector. Quantification was carried out using calibration curves of authentic 
samples against nitrobenzene as standard. Mass balances for all the reactions were higher than $95 \%$. Product yields can be estimated by multiplying conversion by selectivity.

\section{Physicochemical characterization}

Raman spectra were recorded with a $514 \mathrm{~nm}$ laser excitation on a Renishaw Raman spectrometer ("Refelx") equipped with a Leica optical microscopy and a CCD camera. The laser power in the sample was $25 \mathrm{~mW}$. Each spectrum was the average of 20 acquisitions.

XPS measurements were carried out in a SPECS instrument, which includes an XPS spectrometer equipped with a monochromatic X-ray source Al Ka1 (photonic energy $1486.74 \mathrm{eV}$ ), operating under ultra-high vacuum at $1.3 \times 10^{-13} \mathrm{~atm}$. The photoelectrons were collected by a $150 \mathrm{~mm}$ radio Phoibos electron analyzer with a step energy of $30 \mathrm{eV}$. The binding energies were corrected for surface charge effects during measurements using the central level of C1s (284.5 eV) as internal reference. The elementary analyzes (EA) were carried out with a Euro EA 3000.

Thermogravimetric analysis was performed using a Mettler Toledo TGA / SDTA 851 station in the temperature range of $25-900^{\circ} \mathrm{C}$ with a scanning speed of $10^{\circ} \mathrm{C} \mathrm{min}^{-1}$ and an $\mathrm{N}_{2}$ flow of $30 \mathrm{ml} \mathrm{min}^{-1}$.

TEM images were recorded on a JEOL JEM 2100F with an acceleration voltage of $200 \mathrm{kV}$. Isothermal $\mathrm{CO}_{2}$ adsorption measurements were performed using an IGA-3 gravimetric analyzer (Hiden Isochema). Adsorption measurements were carried out at $283 \mathrm{~K}$. XRD pattern was recorded using a a Cubix-pro PANalytical diffractometer. 


\section{Computational details}

Theoretical calculations were carried out by means of the Gaussian 16 program package. Geometry optimization were performed using the pure Perdew, Burke and Ernzerhof functional ${ }^{[38]}$ selecting the Ahlrichs basis set def2-SVP. ${ }^{[39]}$ In addition, density fitting approximation was automatically generated and used. Previous theoretical studies ${ }^{[40]}$ regarding single-walled carbon nanotubes (SWNTs) revealed that dispersion forces dominate the adsorption of $\mathrm{CO}_{2}$ molecules inside the tube, therefore D3 version of Grimme's empirical dispersion correction ${ }^{[41]}$ was also applied. Molecular Electrostatic Potential (MEP) surfaces were also calculated at the same level of theory and plotted onto the van der Waal surface (0.001 a.u. isodensity value).

In all models, the carbon tube models have a constant length of $1.11 \mathrm{~nm}$, whereas the diameter was changed from 0.38 to $0.67 \mathrm{~nm}$ to simulate $\mathrm{G}_{\mathrm{a}-\mathrm{CD}}$ material. Edges of these models are formed by hydrogen atoms, but they were omitted for clarity. For calculation of adsorption profiles, the corresponding gas $\left(\mathrm{N}_{2}, \mathrm{Ar}\right.$ or $\left.\mathrm{CO}_{2}\right)$ was located outside the tube at a non-interacting distance (ca. 11 $\AA$ ), and then, the resulting geometry was optimized to obtain a structure corresponding to a minimum $\left(N_{\text {imag }}=0\right)$. After that, single points calculations were performed to scan the $X$ coordinate for $\mathrm{N}_{2} / \mathrm{Ar} / \mathrm{CO}_{2}$ from out to in the tube modelling the structure of $G_{C D}$. These structures are denoted as $G_{C D}-N_{2}(A r$ or $\mathrm{CO}_{2}$ ) complexes (step size from 0.5 to $0.2 \AA$ ). The energy (given in eV) of each profile point was referred to the calculated minimum structure.

\section{Supporting information}

Supporting information is available from Wiley Online Library or from the author 


\section{Acknowledgements}

Financial support by the Spanish Ministry of Science and Innovation (Severo Ochoa and RTI2018-890237-CO2-1) and Generalitat Valenciana (Prometeo 2017-083) is gratefully acknowledged. A.P. thanks the Spanish Ministry of Education for a Ramon y Cajal research associate contract. S.N. thanks financial support by the Fundación Ramón Areces (XVIII Concurso Nacional para la Adjudicación de Ayudas a la Investigación en Ciencias de la Vida y de la Materia, 2016), Ministerio de Ciencia, Innovación y Universidades RTI2018-099482-A-I00 project and Generalitat Valenciana grupos de investigación consolidables 2019 (ref: AICO/2019/214) project.

\section{References}

[1] X. Cao, Y. Shi, W. Shi, G. Lu, X. Huang, Q. Yan, Q. Zhang, H. Zhang, Small 2011, 7, 3163-8.

[2] B. G. Choi, M. H. Yang, W. H. Hong, J. W. Choi, Y. S. Huh, ACS Nano 2012, 6, 4020-8.

[3] S. Mao, G. Lu, J. Chen, Nanoscale 2015, 7, 6924-43.

[4] R. Munoz, C. Gomez-Aleixandre, Chem. Vap. Deposition 2013, 19, 297-322.

[5] E. Ruiz-Hitzky, M. Darder, F. M. Fernandes, E. Zatile, F. J. Palomares, P. Aranda, Adv. Mater. (Weinheim, Ger.) 2011, 23, 5250-5.

[6] L. Zhang, F. Zhang, X. Yang, G. Long, Y. Wu, T. Zhang, K. Leng, Y. Huang, Y. Ma, A. Yu, Y. Chen, Sci. Rep. 2013, 3, 1408, 9 pp.

[7] A. Primo, E. Sanchez, J. M. Delgado, H. Garcia, Carbon 2014, 68, 777-83.

[8] M.-M. Trandafir, M. Florea, F. Neatu, A. Primo, V. I. Parvulescu, H. Garcia, ChemSusChem 2016, 9, 15659.

[9] A. Dhakshinamoorthy, M. Latorre-Sanchez, A. M. Asiri, A. Primo, H. Garcia, Catal. Commun. 2015, 65, 10-3.

[10] A. Primo, P. Atienzar, E. Sanchez, J. M. Delgado, H. García, Chemical communications 2012, 48, 9254-6.

[11] H. G. Baldovi, F. Albarracin, M. Alvaro, B. Ferrer, H. Garcia, ChemPhysChem 2015, 16, 2094-8.

[12] I. Esteve-Adell, J. He, F. Ramiro, P. Atienzar, A. Primo, H. Garcia, Nanoscale 2018, 10, 4391-7.

[13] M. L. Bender, M. Komiyama, Cyclodextrin Chemistry, Springer, 1978.

[14] J. Szejtli, Chem Rev 1998, 98, 1743-54.

[15] W. Saenger, Angew. Chem. 1980, 92, 343-61.

[16] K. A. Connors, Chem. Rev. (Washington, D. C.) 1997, 97, 1325-57.

[17] J. E. St. Dennis, P. Venkataraman, J. He, V. T. John, S. J. Obrey, R. P. Currier, M. Lebron-Colon, F. J. Sola, M. A. Meador, Carbon 2010, 49, 718-22.

[18] F. Trotta, M. Zanetti, G. Camino, Polym. Degrad. Stab. 2000, 69, 373-9.

[19] M. S. Mettler, S. H. Mushrif, A. D. Paulsen, A. D. Javadekar, D. G. Vlachos, P. J. Dauenhauer, Energy Environ. Sci. 2012, 5, 5414-24.

[20] S. Navalon, A. Dhakshinamoorthy, M. Alvaro, M. Antonietti, H. García, Chemical Society Reviews 2017, 46, 4501-29.

[21] L. M. Malard, M. A. Pimenta, G. Dresselhaus, M. S. Dresselhaus, Phys. Rep. 2009, 473, 51-87. 
[22] A. C. Ferrari, Solid State Commun. 2007, 143, 47-57.

[23] M. Latorre-Sanchez, A. Primo, H. Garcia, Angew. Chem., Int. Ed. 2013, 52, 11813-6.

[24] D. W. Breck, Zeolite Molecular Sieves: Structure, Chemistry, and Use, Wiley-Interscience, 1974.

[25] H. Marsh, Carbon 1987, 25, 49-58.

[26] J. Rouquerol, F. Rouquerol, P. Llewellyn, G. Maurin, K. S. Sing, Adsorption by powders and porous solids: principles, methodology and applications, Academic press, 2013.

[27] J. C. Groen, L. A. Peffer, J. Pérez-Ramírez, Microporous and mesoporous materials 2003, 60, 1-17.

[28] S. Navalon, A. Dhakshinamoorthy, M. Alvaro, M. Antonietti, H. Garcia, Chem. Soc. Rev. 2017, 46, 450129.

[29] A. Primo, V. Parvulescu, H. Garcia, J. Phys. Chem. Lett. 2017, 8, 264-78.

[30] A. Santiago-Portillo, J. F. Blandez, S. Navalon, M. Alvaro, H. Garcia, Catal. Sci. Technol. 2017, 7, 1351-62.

[31] A. Santiago-Portillo, M. Cabrero-Antonino, M. Alvaro, S. Navalon, H. Garcia, Chem. - Eur. J. 2019, 25, 9280-6.

[32] M. T. Maurette, E. Oliveros, P. P. Infelta, K. Ramsteiner, A. M. Braun, Helv. Chim. Acta 1983, 66, 722-33.

[33] H. J. Guiraud, C. S. Foote, J. Am. Chem. Soc. 1976, 98, 1984-6.

[34] L. Li, Y. Abe, K. Kanagawa, N. Usui, K. Imai, T. Mashino, M. Mochizuki, N. Miyata, Anal. Chim. Acta 2004, 512, 121-4.

[35] S. E. Page, W. A. Arnold, K. McNeill, J. Environ. Monit. 2010, 12, 1658-65.

[36] J. C. Espinosa, S. Navalon, M. Alvaro, H. Garcia, ChemCatChem 2016, 8, 2642-8.

[37] A. Primo, A. Franconetti, M. Magureanu, N. B. Mandache, C. Bucur, C. Rizescu, B. Cojocaru, V. I. Parvulescu, H. Garcia, Green Chem. 2018, 20, 2611-23.

[38] J. P. Perdew, K. Burke, M. Ernzerhof, Phys. Rev. Lett. 1996, 77, 3865-8.

[39] F. Weigend, R. Ahlrichs, Phys. Chem. Chem. Phys. 2005, 7, 3297-305.

[40] D. Quinonero, A. Frontera, P. M. Deya, J. Phys. Chem. C 2012, 116, 21083-92.

[41] S. Grimme, J. Antony, S. Ehrlich, H. Krieg, J. Chem. Phys. 2010, 132, 154104/1-/19. 